\title{
OS SENTIDOS DE "COTA" NO JULGAMENTO DA ARGUIÇÃO DE DESCUMPRIMENTO DE PRECEITO FUNDAMENTAL-ADPF 186
}

\author{
THALITA NOGUEIRA DE SOUZA ${ }^{1}$, NEUZA B. DA SILVA ZATTAR ${ }^{2}$
}

Programa de Pós-Graduação em Linguística, Universidade do Estado de Mato Grosso Av. Santos Dumont s/n - Bloco II. Centro de Pesquisa e Pós-Graduação em Linguagem, Cidade Universitária, Bairro DNER, 78 200-000 - Cáceres-MT, Brasil

nogueirathalita@outlook.com, neuza.zattar@gmail.com

\begin{abstract}
Resumo. Este texto filia-se à disciplina teórica Semântica do Acontecimento desenvolvida por Guimarães (2002). Teve como objetivo analisar a expressão linguística "cota”, enunciada no julgamento da Arguição de Descumprimento de Preceito Fundamental-ADPF186, ajuizada no Supremo Tribunal Federal-STF pelo Partido Democratas-DEM, requerendo que o sistema de "cotas" da Universidade de Brasília-UnB fosse considerado inconstitucional. Nas análises, foi possível observar que a enunciação da expressão "cota" tem uma determinação social e histórica exposta à exterioridade, o que permite compreender que "cota" pode ter outros sentidos, além da reserva de vaga para estudantes no ensino superior.
\end{abstract}

Palavras-chave: Semântica do Acontecimento; cotas; voto.

\begin{abstract}
This work is affiliated to Semantics of Event developed by Guimarães (2002). Our objective was to present an analysis of the linguistic expression "quota", uttered within the trial "Arguição de Descumprimento de Preceito Fundamental-ADPF186", lawsuit filed at Federal Supreme Court-STF by Democrats Party (DEM), requiring that the system of quotas in the University of Brasilia $(U n B)$ should be considered unconstitutional. In this analysis, it will be possible to observe that the enunciation of the expression "quota" has a social and historical determination exposed to the exteriority, which leads to the comprehension that "quota" can produce other meaning effects besides the one that could merely reproduce "a reserve of positions for undergraduate students".
\end{abstract}

Keywords: Semantics of the event; quotas; vow.

\footnotetext{
1 Mestre em Linguística pela Universidade do Estado do Mato Grosso (UNEMAT-Cáceres/MT). http://lattes.cnpq.br/8931765621516749.

${ }^{2}$ Doutora em Linguística pela Unicamp. Professora no Programa de Pós-Graduação em Linguística da Universidade do Estado de Mato Grosso (UNEMAT-Cáceres/MT).
} 


\section{Introdução}

Entre as questões sociais e políticas debatidas na mais alta corte brasileira, o Supremo Tribunal Federal-STF, destacamos o tema das "cotas" raciais que foi objeto da Arguição do Descumprimento de Preceito Fundamental-ADPF186, ajuizada em 2009 pelo Partido Democratas-DEM no Supremo Tribunal Federal-STF, contra a política de "cotas" raciais implantada pela Universidade Nacional de Brasília (UnB). O Partido requereu que as "cotas" raciais fossem declaradas como inconstitucionais, por verificar que o modelo de seleção se mostrava inadequado ao incluir foto e entrevista, para examinar a aparência do candidato ao vestibular.

No Brasil, as "cotas" raciais têm origem nas políticas de ações afirmativas ${ }^{3}$, que visam à eliminação de desigualdades e segregações. As "cotas" raciais para acesso às universidades pretendem reparar as desigualdades historicamente sofridas pelas minorias étnico-raciais ao longo da história, tendo em vista que os dispositivos da abolição da escravatura não garantiram aos negros os mesmos direitos dados pela Constituição Imperial de 1824 aos cidadãos brancos. Em relação às "cotas", Vasconcelos (2007) aponta que no Brasil há uma ampla discussão envolvendo a questão racial, principalmente entre antropólogos, sociólogos, historiadores. Esse fato deve-se principalmente à miscigenação da população brasileira que dificulta a identificação da origem racial dos indivíduos.

Albuquerque e Filho (2006, pp. 205, 206) relatam que a miscigenação foi uma das soluções encontradas para o problema de civilidade no Brasil. Durante a Primeira República (1889-1930), o Estado investiu na imigração de trabalhadores europeus com o objetivo de embranquecer a raça negra, esperando que, em aproximadamente cem anos, a porcentagem de mulatos fosse quase nula. A miscigenação dividia opiniões na sociedade brasileira, pois a mistura de raças garantia a "civilização", mas, o fato de as raças supostamente evoluírem com o tempo, levava a crer, segundo os autores, que a mestiçagem geraria um tipo biológico e social degenerado, incapaz mentalmente: o mulato. Logo, as diferenças raciais promoveram um cenário político de exclusão para a população negra.

A luta para reduzir as desigualdades instauradas no Brasil ganhou força e visibilidade, no final do século XX, quando os Movimentos Sociais Negros-MSN começaram a promover no cenário social, ações de enfrentamento para os principais problemas da população negra, referentes à saúde, ao trabalho e principalmente à educação. Nesse ínterim, Santos (2007) salienta que, o governo do Presidente Fernando

\footnotetext{
${ }^{3} \mathrm{O}$ conceito de ação afirmativa é amplo. Apresentamos o encontrado no Dicionário de Relações Étnicas e Raciais, organizado por Ellis Cashmore (2000, p. 31): ação afirmativa é uma política pública que é voltada para reverter as tendências históricas que conferiram às minorias e às mulheres uma posição de desvantagem, particularmente nas áreas de educação e emprego. Ela visa ir além da tentativa de garantir igualdade de oportunidades individuais ao tornar crime a discriminação, e tem como principais beneficiários os membros de grupos que enfrentaram preconceitos.

4 As questões sobre a miscigenação e a civilização no Brasil estão relacionadas às teorias raciais desenvolvidas a partir da segunda metade do século XIX, [...] que, populares entre os intelectuais na Europa, [...] colocaram as diversas sociedades numa escalada ao progresso, estando à frente da caminhada, França e Inglaterra, pois nesses países se encontravam uma raça humana específica: a branca, ariana ou caucasoide. Construía-se, assim, um determinismo biológico que já colocava como ponto de partida a questão racial para o alcance da civilização ( $c f$. AMORIM, 2013, p. 65).
} 
Henrique Cardoso foi pioneiro em reconhecer a existência da discriminação racial no Brasil, frisando que algo precisava ser feito para que a desigualdade fosse superada. $\mathrm{O}$ governo seguinte, do presidente Luiz Inácio Lula da Silva (2002), também reconheceu o problema da discriminação racial, tomando diversas medidas, entre delas, a criação de "cotas" raciais para ingresso no ensino superior.

O novo paradigma instituído pelas ações do Governo Federal possibilitou à Universidade de Brasília-UnB tornar-se a primeira universidade federal a aderir a "cota" no Brasil. Conforme a Resolução n ${ }^{\circ} 38 / 2003$ da CEPE, a UnB reservou, para o vestibular do segundo semestre de 2004, $20 \%$ das vagas para negros (pretos e pardos) e $10 \%$ vagas para indígenas. O candidato ao vestibular, para aprovação pelo sistema de "cota", passava por uma banca de avaliação para comprovar sua origem racial. Esse sistema causou inúmeras discussões devido à dificuldade de reconhecimento da situação social do negro ou pardo, apenas pelo critério da aparência, uma vez que o conceito de raça é entendido no Brasil como social e não biológico. (NORÕES, 2011).

As considerar essas questões que suscitam muitas discussões, este trabalho tem o propósito de analisar os sentidos da expressão "cota" nos votos dos Ministros do Supremo Tribunal Federal-STF no acontecimento de linguagem "Arguição de Descumprimento de Preceito Fundamental - ADPF186"5.

Para a análise, mobilizamos os conceitos teóricos da Semântica do Acontecimento, como: "enunciação", "acontecimento", "temporalidade", "político", "espaço de enunciação", "cena enunciativa", "divisão do Locutor" e os procedimentos teóricometodológicos desenvolvidos por Guimarães (2005, 2011). A partir desses constructos teóricos podemos entender que os sentidos da expressão linguística "cota" "significam no enunciado pela relação que têm com o acontecimento em que funcionam". (GUIMARÃES, 2005, p. 5).

\section{A Semântica do Acontecimento}

Conforme Guimarães (2005, p. 7), "a análise do sentido da linguagem deve localizar-se no estudo da enunciação, do acontecimento do dizer". Para o autor, a enunciação é

[...] um acontecimento de linguagem perpassado pelo interdiscurso, que se dá como espaço de memória no acontecimento. É um acontecimento que se dá porque a língua funciona ao ser afetada pelo interdiscurso. É, portanto, quando o indivíduo se encontra interpelado como sujeito e se vê como identidade que a língua se põe em funcionamento. (idem, 2010, p. 70)

\footnotetext{
${ }^{5}$ É um tipo de ação, ajuizada exclusivamente no STF, que tem por objeto evitar ou reparar lesão a preceito fundamental, resultante de ato do Poder Público. Neste caso, diz-se que a ADPF é uma ação autônoma. Entretanto, esse tipo de ação também pode ter natureza equivalente à ADI, ação que tem por finalidade declarar que uma lei ou parte dela é inconstitucional, ou seja, contraria a Constituição Federal. A ADPF é disciplinada pela Lei Federal 9.882/99. Os legitimados para ajuizá-la são os mesmos da ADI. Não é cabível ADPF quando existir outro tipo de ação que possa ser proposto. Disponível em http://www.stf.jus.br/portal/glossario/verVerbete.asp?letra=A\&id=481. Acesso em 10 fev. 2016.
} 
Nessa direção, Guimarães (2012) apresenta uma nova conceituação de "acontecimento de linguagem". Além da língua e do sujeito, elementos importantes para esse conceito, o autor introduz o real, "a que o dizer se expõe ao falar dele", e a temporalidade. Essa perspectiva permite compreender que não é o sujeito que temporaliza, é o acontecimento que instala sua própria temporalidade.

Para o semanticista (2005, p. 12), a temporalidade

se configura por um presente que abre em si uma latência de futuro (uma futuridade), sem a qual não há acontecimento de linguagem, sem a qual nada é significado, pois sem ela (a latência de futuro ) nada há aí de projeção de interpretável. O acontecimento tem como seu um depois incontornável próprio do dizer. Todo acontecimento de linguagem significa por que projeta em si um futuro.

Desse modo, o que é dito no presente só significa porque o acontecimento rememora um passado e projeta uma futuridade, ou seja, abre-se para novas interpretações. Tomar a enunciação como um acontecimento de linguagem que temporaliza, implica compreender que, para Guimarães (2005, p. 12), o acontecimento "é sempre uma nova temporalização, um novo espaço de conviviabilidade de tempos, sem o qual não há sentido, não há acontecimento de linguagem, não há enunciação”.

No acontecimento se dá a relação do sujeito com a língua, enquanto uma prática política no sentido de que, para Guimarães (2005, p. 16), o político é "caracterizado pela contradição de uma normatividade que estabelece (desigualmente) uma divisão do real e a afirmação do pertencimento dos que não estão incluídos". Este modo de caracterizar o político nos permite compreender que ele afeta e divide materialmente a linguagem por uma contradição que instala um conflito de sentidos no centro do dizer.

Outra questão importante ao tratar o acontecimento de linguagem como político é compreender como se constituem os espaços de enunciação. Para Guimarães (2005, p. 18), esses espaços são

[...] espaços de funcionamento de línguas, que se dividem, redividem, se misturam, desfazem, transformam por uma disputa incessante. São espaços "habitados" por falantes, ou seja, por sujeitos divididos por seus direitos ao dizer e aos modos de dizer.

Para Guimarães (2005), é o espaço de enunciação que torna a língua uma prática política, uma vez que falar é assumir a palavra nesse espaço dividido entre línguas e falantes. Enunciar é estar na língua em funcionamento. Para o autor, a assunção da palavra se dá em cenas enunciativas, caracterizadas como modos específicos de acesso à palavra, dadas as relações entre as figuras de enunciação e as formas linguísticas. Desse modo, a cena enunciativa é caracterizada como

[...] um espaço particularizado por uma deontologia específica de distribuição dos lugares de enunciação no acontecimento. Os lugares enunciativos são configurações especificas do agenciamento enunciativo para "aquele que fala" e "aquele para quem se fala". $\mathrm{Na}$ cena enunciativa "aquele que fala ou "aquele para quem se fala" não são pessoas, mas uma configuração do agenciamento enunciativo. São 
lugares constituídos pelos dizeres e não pessoas donas de seu dizer. (GUIMARÃES, 2005, p. 22)

As cenas enunciativas se constituem como um espaço de distribuição dos lugares de enunciação, "aquele que fala" (locutor) e "para quem se fala" (alocutário), pois os falantes não são donos do seu dizer. E, além disso, o direito ao dizer é político, desigualmente dividido. Conforme o autor (2005), a distribuição destes lugares se faz pela temporalização própria do acontecimento, e a temporalidade específica do acontecimento é o fundamento da cena enunciativa.

Desse modo, assumir a palavra para Guimarães (2005) é se colocar no lugar de quem enuncia, ou seja, como Locutor, que ele chama de L (L maiúsculo). Este L se apresenta como a própria fonte do dizer. Para falar do lugar de L é preciso estar afetado por lugares sociais autorizados a falar, ou seja, de um lugar social de locutor chamado por Guimarães de locutor- $\mathrm{x}$.

Para o semanticista (2005), existem ainda os "lugares de dizer" ocupados pelo que ele caracteriza de enunciadores que

[...] se apresentam sempre como a representação da inexistência dos lugares sociais de locutor. E embora se apresente como independentes da história ou fora da história, são lugares próprios da história. Temos então enunciadores como: enunciador-individual, quando a enunciação representa o Locutor como independente da história; enunciadorgenérico quando a enunciação representa o locutor como difuso num todos em que o indivíduo fala como e com outros indivíduos; enunciador universal, quando a enunciação representa o Locutor fora da história e submetido ao regime de verdadeiro ou falso. (idem, 2005, p. 26)

Considerando que a prática da linguagem se realiza através de textos, é fundamental trazermos para este trabalho o conceito de texto desenvolvido por Guimarães (2011).

\section{O texto e os procedimentos de análise}

Conforme o lugar teórico ao qual nos filiamos, só é possível analisar o sentido de uma expressão linguística num dado enunciado, se considerarmos que esse enunciado integra um texto. Assim, é fundamental dizer o que se entende por texto. Segundo Guimarães (2011, p. 19), o texto "é uma unidade de sentido que integra enunciados no acontecimento de enunciação". Ou seja, um texto não é um conjunto de enunciados, nem uma unidade composta por enunciados. $\mathrm{O}$ texto se caracteriza por uma relação com outras unidades de linguagem, os enunciados, que significam nessa relação. E não se trata de uma construção caracterizada pela segmentalidade. "A integração se faz por uma relação transversal entre elementos diversos e a unidade a qual se reportam" (idem, 2011, p. 43). O funcionamento do texto está relacionado a procedimentos de constituição de sentido não segmentais, pois, o texto não é linear. 
Desse modo, analisar textos, para Guimarães (2011, p. 43), é mostrar o funcionamento de expressões linguísticas em enunciados que integram um determinado texto, ou seja, um acontecimento de enunciação.

O primeiro passo para essa tarefa é tomar um recorte, "um fragmento do acontecimento da enunciação", considerando os seguintes procedimentos:

(1) Toma-se um recorte qualquer e produz-se uma descrição de seu funcionamento;

(2) Interpreta-se o seu sentido na relação com o texto em que está integrado;

(3) Chega-se a, ou toma-se outro recorte e faz-se dele uma descrição;

(4) Interpreta-se seu sentido na relação com o texto em que está integrado, tendo em vista a interpretação feita do primeiro recorte;

(5) Busca-se um novo recorte, etc., até que a compreensão produzida pelas análises se mostre suficiente para o objetivo especifico da análise.

(GUIMARÃES, 2011, pp. 44, 45)

O material analítico deste trabalho é constituído dos textos dos votos formulados pelos Ministros do STF no acontecimento "Arguição de Descumprimento de Preceito Fundamental 186", nas sessões dos dias 25 e 26 de abril de $2012^{6}$.

\title{
3. Análise
}

Para as análises, destacamos três Recortes (R1, R2, R3), encadeados em sequências enunciativas (SE1, SE2, SE3), dos votos formulados por: Ricardo Lewandowisk (relator do processo) e dos Ministros Rosa Weber e Gilmar Mendes, ambos do $\mathrm{STF}^{7}$.

\begin{abstract}
Recorte 1
(SE1) As políticas de ação afirmativa, compreendidas como medidas que têm como escopo "reparar ou compensar os fatores de desigualdade factual com medidas de superioridade jurídica", não configuram meras concessões do Estado, mas consubstanciam deveres que se extraem dos princípios constitucionais. (SE2) [...] não há dúvidas, a meu sentir, quanto à constitucionalidade da política de reserva de vagas ou do estabelecimento de cotas nas universidades públicas, visto que a medida encontra amparo no próprio Texto Magno [...] a política de reserva de vagas não é, de nenhum modo, estranha à Constituição, a qual, em seu art. 37, VIII, consigna o seguinte: [...] a lei reservará percentual dos cargos e empregos públicos para as pessoas portadoras de deficiência e definirá os critérios de sua admissão (SE3) [...] as
\end{abstract}

\footnotetext{
6 Esse julgamento foi organizado da seguinte forma: anterior às cenas de enunciação dos votos, a sessão foi aberta pelo presidente do Supremo Tribunal Federal, Ministro Ayres Brito; em seguida, o Ministrorelator Ricardo Lewandowski apresentou o resumo do seu voto-relatório. Na sequência, falaram as advogadas do requerente partido DEM, e dos interessados (Conselho de Ensino, Pesquisa e Extensão da Universidade de Brasília - CEPE, Reitor da Universidade de Brasília, Centro de Seleção e de Promoção de Eventos da Universidade de Brasília - CESPE/UnB). A favor da UnB, falaram autoridades da Advocacia Geral da União e do Ministério Público. Além dos citados, houve também espaço para os amici curiae (amigos da corte): dois se manifestaram a favor da postulação do partido Democratas, e sete a favor dos interessados, UnB.

${ }^{7}$ Os textos estão registrados em vídeo e disponíveis em: http://www.youtube.com/stf. Acesso em 10 jan. 2017.
} 
políticas de ação afirmativa adotadas pela Universidade de Brasília (i) têm como objetivo estabelecer um ambiente acadêmico plural e diversificado, superando distorções sociais historicamente consolidadas, (ii) revelam proporcionalidade e a razoabilidade não concernentes aos meios empregados e aos fins perseguidos, (iii) são transitórias e preveem a revisão periódica de seus resultados, e (iv) empregam métodos seletivos eficazes e compatíveis com o princípio da dignidade humana, julgo improcedente esta ADPF.

O R1 extraído do texto Relatório ${ }^{8}$ é constituído pelo voto do Ministro Ricardo Lewandowski na ADPF-186, que introduz a cena do julgamento, fundamentando os pontos discutidos durante os trâmites do processo.

Essa primeira cena enunciativa, espaço de constituição das figuras enunciativas, "aquele que fala" e "aquele para quem se fala", se dá no espaço de enunciação da Língua Portuguesa oficial, que, para Guimarães (2005 b, p. 11), é a "língua de um Estado, aquela que é obrigatória nas ações formais do Estado, nos seus atos legais". Contudo, a "língua" pode variar e não ser a mesma para todos falantes, pois "a língua é dividida no sentido de que ela é atravessada pelo político”. (GUIMARÃES, 2005, p. 18)

Sobre o falante, figura constituída pelo espaço de enunciação, temos inscrito nessa cena a figura enunciativa do Locutor, origem do dizer (Ricardo Lewandowisk), que se divide em locutor $\mathrm{x}$ ( $\mathrm{x}=$ Ministro relator), autorizado pelo lugar social, jurídico e institucional a ordenar, dirigir o processo e preparar o Relatório. Esta divisão do Locutor só é possível por que, de acordo com Guimarães (2005, p. 30),

[...] falar e fazer-se sujeito é estar numa região do interdiscurso, de uma memória de sentidos (ORLANDI,1999). Assim ser sujeito é estar afetado por esse esquecimento que se significa nessa posição. Deste modo a representação do Locutor se constitui neste esquecimento e é isto que divide o Locutor e apaga o locutor $\mathrm{x}$.

Temos, assim, um Locutor autorizado a dizer do lugar social de locutor-Ministro relator e o alocutário-x, "aqueles para quem se fala", os Ministros, os representantes da Universidade de Brasília e do partido Democratas. Ao enunciar, o dizer do locutorMinistro relator assimila o lugar da universalização dos direitos constitucionais, ou seja, de enunciador-universal, um lugar que significa o Locutor "como submetido ao regime de verdadeiro ou falso". (GUIMAR ÃES, 2005, p. 26)

Assim, na SE1, o agenciamento político do locutor-Ministro relator, constituído por uma memória de enunciações, permite dizer que as "cotas", enquanto uma das medidas das ações afirmativas, "não" significam "meras concessões do Estado, mas consubstanciam deveres" pautados nos princípios constitucionais. Ou seja, os sentidos de "cotas" dados anteriormente como "meras concessões" para reparar ou compensar as desigualdades sociais, deslocam-se pela presença da expressão linguística "mas", que

\footnotetext{
${ }^{8} C f$. Regimento Interno do STF, que refere-se ao resumo do que ocorreu no processo, o qual a secretaria remete previamente cópias a todos os Ministros para que sirva de base para que demais Ministros formulem seus votos, primeiramente por escrito, para posterior publicação, e oral, no momento do julgamento. Disponível em http://www.stf.jus.br/arquivo/cms/legislacaoRegimentoInterno/anexo/RISTF.pdf. Acesso em 15 maio 2016.
} 
redireciona os sentidos de "cotas" para "deveres" constitucionais. Desse modo, a "cota", como dever do Estado, não deixa nenhuma dúvida quanto a sua "constitucionalidade de política de reserva de vagas".

Com esses argumentos, o Relatório no qual os Ministros vão se pautar para formular os votos, deixa entrever os sentidos atribuídos às "cotas", uma vez que os sentidos da enunciação do voto do locutor-Ministro relator são "os efeitos da memória e do presente do acontecimento: posições de sujeito, cruzamento de discursos no acontecimento". (GUIMARÃES, 2010, p. 70). Assim, mesmo que a palavra "cotas" não apareça no dizer do locutor-Ministro relator, ela significa pela expressão "políticas de ação afirmativa", uma vez que as "cotas" raciais se constituem como uma das possíveis ações de reparação destinadas aos que foram sócio-historicamente excluídos.

Compreendemos que a expressão "ação afirmativa" empregada nessa cena enunciativa ${ }^{9}$, rememora o dito no Art. $2^{\circ}$, inciso II, da Convenção para a Eliminação de Todas as Formas de Discriminação Racial, da Organização das Nações Unidas, criada pelo Governo federal, segundo o qual, as ações afirmativas são

[...] medidas especiais e concretas para assegurar como convier o desenvolvimento ou a proteção de certos grupos raciais de indivíduos pertencentes a estes grupos com o objetivo de garantir-lhes, em condições de igualdade, o pleno exercício dos direitos do homem e das liberdades fundamentais $[\ldots]$

Esta definição projeta o interpretável de que há desigualdades para certos grupos raciais, rememorando no presente do acontecimento as desigualdades sociais que privaram os negros do acesso a direitos sociais e políticos, principalmente, emprego, educação etc., direitos que vêm sendo assegurados por essas políticas regidas pela Constituição Federal, lugar que garante a todos os brasileiros os mesmos direitos.

$\mathrm{Na}$ SE2, observamos que o lugar social de Ministro-relator fica latente pela forma enunciativa "a meu sentir", pois conforme Oliveira (2013), o acontecimento agencia o Locutor fazendo com que o mesmo signifique num lugar de dizer, ou seja, a representação desse "Eu" como fonte do dizer não é um gesto consciente, mas sim um agenciamento enunciativo no qual o lugar social de locutor é velado pelo enunciador universal, ${ }^{10}$ uma vez que o Locutor enuncia a partir da Constituição Federal.

Ainda na SE2, entendemos que a enunciação do artigo art. 37, inciso VIII da Constituição, que diz sobre o amparo à reserva de vaga "cota" para pessoa com deficiência, possibilita uma futuridade de sentidos que significa a "cota" racial como um direito constitucional que pode ser incluído na Carta Magna pelo mesmo lugar da pessoa com deficiência. Consideramos essa hipótese, pois ambas têm o objetivo de beneficiar e incluir minorias pertencentes à diferentes lugares sociais. Essa relação mostra que estamos diante do funcionamento de uma contradição que é própria do político, "caracterizado pela contradição de uma normatividade que estabelece (desigualmente)

\footnotetext{
${ }^{9}$ Disponível em: http://www.stf.jus.br/arquivo/cms/noticiaNoticiaStf/anexo/ADPF186RL.pdf. Acesso em 10 maio 2016.

${ }^{10}$ Entendemos que o "Eu" no agenciamento enunciativo, ao longo das análises, configura sempre o lugar de dizer de enunciador-universal.
} 
uma divisão do real e a afirmação de pertencimento dos que não estão incluídos" (GUIMARÃES, 2005, p. 16).

Na SE3, a expressão "políticas de ação afirmativas", que nesse acontecimento designam "cotas", estabelece uma relação de sentidos com as formas linguísticas: "superando distorções sociais historicamente consolidadas"; "proporcionalidade e razoabilidade"; "transitoriedade"; "seletividade". Ou seja, nessa cena a palavra "cota" passa a significar pelos objetivos que devem ser considerados na decisão de constitucionalidade. Essa relação pode ser explicada, segundo Guimarães (2011), como uma relação de integração que se dá pela transversalidade, quer dizer pelo modo como a expressões linguísticas atravessam o texto, produzindo novos sentidos para "cota" a cada novo acontecimento.

Salientamos ainda na SE3, que o dito no item (iv) sobre as políticas afirmativas, "cotas", produz uma contradição de sentidos, visto que trata os métodos seletivos como "[...] eficazes e compatíveis com o princípio da dignidade humana [...]". No entanto, o sistema de "cotas" da UnB resulta como sabemos em várias incongruências, como por exemplo, irmãos gêmeos serem considerados de raças diferentes.

Enunciar que os métodos seletivos (foto e entrevista) são compatíveis com o princípio da dignidade humana, ${ }^{11}$ rememora o Art. 01, inciso III da Constituição, projetando o sentido de que a "cota" não contraria o valor individual nem o direito à igualdade do ser humano, o que instala um conflito no centro do dizer pela maneira como o real é apreendido. Ou seja, como um método de seleção, que discrimina apenas pela aparência, pode estar em harmonia com a Constituição? Essa questão produz sentidos à medida que as políticas de ações afirmativas, "cotas", significam por uma "uma divisão normativa e desigual do real” (GUIMARÃES, 2005, p. 16).

\section{Recorte 2}

(SE1) A política de cotas é imediata e temporária, tendendo a desaparecer na medida em que as desigualdades sejam diminuídas. Também como eu enfatizei [...], o sistema de cotas visa oportunizar, no caso da UnB, aos negros, o acesso à universidade brasileira com vista ao equilíbrio às oportunidades sociais. (SE2) Assim, as razões se inclinam para manutenção do sistema que é um critério concreto e temporário de tratamento desigual para realização de uma igualdade material, que levará à justificação da presunção geral de igualdade consagrada na nossa Constituição. [...] (SE3) Concluo dizendo que, eu entendo que os princípios constitucionais, as normas constitucionais, os postulados da nossa Constituição que foram apontados pelo autor da ação como violados, na minha leitura e na minha compreensão, são justamente os preceitos, os postulados, os princípios, as normas que levam data máxima vênia a total improcedência da ação, é como voto, Sr. Presidente.

\footnotetext{
11 Refere-se àquele que reconheceu na dignidade pessoal a prerrogativa de todo ser humano em ser respeitado como pessoa, de não ser prejudicado em sua existência (a vida, o corpo e a saúde) e de fruir de um âmbito existencial próprio. Disponível em file:///C:/Users/MICROr1/Downloads/2182-8216-1-PB.pdf. Acesso em 06 jun. 16.
} 
O R2 foi extraído do voto da Ministra Rosa Weber, a segunda a sustentar o voto oralmente na cena do julgamento.

Na SE1, o locutor-Ministro assimila o lugar de dizer de enunciador-universal ao definir "política de cotas" como "imediata e temporária". Esses predicados funcionam como argumento próprio das "políticas de cotas", produzindo sentidos de imediatismo, de provisoriedade, em oposição ao permanente/duradouro.

A adoção da "cota" como política imediata e transitória significa que a "cota" tende a desaparecer quando a desigualdade diminuir, significando que "cota" $\mathrm{e}$ desigualdade são interdependentes. Nesse sentido, a "cota" produz sentidos à medida que "o estabelecimento da desigualdade se apresenta como necessária à vida social, e a afirmação de pertencimento e de igualdade perpassa por esta interdependência" (GUIMARÃES, 2005, p. 18).

Ainda na SE1, a "cota" significa um sistema em funcionamento que possibilita ao negro competir e conquistar um lugar social, uma vez que proporciona equilíbrio, ou seja, condições de igualdade para o acesso à educação superior.

Na SE2, o dizer do locutor-Ministro evoca a Constituição como sendo (nossa), ou seja, de todos os brasileiros, e assimila o lugar de enunciador coletivo, "lugar de dizer que se caracteriza por ser a voz de todos com uma única voz” (idem, p. 38).

Porém, ao enunciar que a Constituição é "nossa", essa propriedade não significa que todos os brasileiros têm direitos iguais, visto que o acesso à "cota" significa um tratamento desigual (racial) para promover a igualdade dita como material (social). Percebemos então que há um conflito de sentidos no dizer do enunciador-coletivo, pois a própria da Constituição em seu Art. 05 diz: "todos são iguais perante a lei, sem distinção de qualquer natureza [...]". Ou seja, observamos conforme Guimarães (2005), um conflito próprio do político que está sempre dividido pela desmontagem da contradição que o constitui.

$\mathrm{Na}$ SE3, o dizer do locutor-Ministro se representa pela forma da primeira pessoa "Eu", "minha", que nos leva a perceber o esquecimento de que se enuncia do lugar social de ministra do STF, dando a impressão que a afirmação da não violação da Constituição é feita pelo Locutor enquanto origem do que diz e não pelo lugar social autorizado a dizer. Nesse sentido, os argumentos do Partido DEM, de que o sistema de "cotas" viola postulados constitucionais, são refutados pelo locutor-Ministro ao dizer: "são justamente os preceitos, os postulados, os princípios, as normas (da Constituição) que levam [...] a total improcedência da ação".

Notamos ainda que a cena enunciativa em análise se institui no espaço de enunciação das ações formais e atos legais do Estado, ou seja, da Língua Portuguesa oficial que tem sua origem no Latim, língua que, segundo Furlan (2006, p. 16), "os romanos elaboraram o magistral código jurídico, cujas categorias fundamentam o Direito Moderno, que ainda exprime em Latim inúmeros conceitos, normas e princípios jurídicos". Assim, compreendemos que a expressão data máxima vênia ${ }^{12}$ funciona enfatizando sentidos de que a "cota" não viola a Constituição.

12 Conforme Houaiss (2009), é uma expressão respeitosa com a qual se inicia uma argumentação, contrariando a opinião de outrem; com a devida licença. 


\section{Recorte 3}

(SE1) Eu tenho muitas dúvidas, e eu deixo isso no meu voto em relação ao critério puramente racial, porque também aqui não se contempla, ou melhor, permite-se uma possível distorção que, pessoas embora consideradas de uma determinada raça, mas que tiveram um desenvolvimento educacional absolutamente adequado, agora sejam convidadas a trilhar esse caminho facilitário das cotas, por que não se leva em conta o referencial de índole social [...]. (SE2) Nesse sentido, eu não chancelaria a fórmula como totalmente constitucional, mas eu diria na linha do que a gente vem sustentando aqui, as chamadas sentenças intermédias, é uma lei ainda constitucional, quer dizer um modelo que pode tender se for mantido, se não for revisto, para um quadro de inconstitucionalidade, quando se apontam as distorções que têm sido apontadas e elas são sérias, tanto a possibilidade de cooptação, ricos que se aproveitam da cota, pervertendo, portanto, o sistema, ou decisões discricionárias e até arbitrárias de servidores das universidades, nesse órgão de seleção racial, Sr. Presidente, não é um bom modelo, especialmente numa sociedade miscigenada, há uma dificuldade muito grande em relação a isso. (SE3) [...] Eu tenho dúvida de que esse modelo possa prosseguir e não ter questionamentos se não houver os necessários aprimoramentos, mas com essas observações, eu julgo improcedente a ação.

O R3 foi extraído do voto do Ministro Gilmar Mendes, o quarto a sustentar oralmente o voto no acontecimento do julgamento da ADPF 186. Na SE1, do recorte acima, há uma contradição de sentidos entre o método de seleção da UnB, que decide apenas pela aparência física (racial) quem terá direito à "cota", e o objetivo maior da "cota", que é corrigir a desigualdade social. Esta contradição projeta sentidos de que a "cota" é um "caminho facilitário" por incluir negros ricos ou que tiveram e têm condições de acesso à educação, ou seja, pessoas que não necessitam da "cota".

Na SE2, a língua se divide no espaço de enunciação, e esta divisão se dá pela disparidade do locutor-Ministro em enunciador-universal, lugar que diz sobre a verdade dos fatos e que nega a constitucionalidade da "cota", e do enunciador-coletivo (a gente = nós), que representa a coletividade dos Ministros do STF, e ainda aceita a "cota" como constitucional.

Observamos que o modo de dizer do locutor-Ministro muda no espaço de enunciação, ora tomado pela Língua Portuguesa oficial, ora pela língua coloquial (a gente). Essa mudança acontece porque as línguas se misturam, se dividem, por uma disputa incessante no espaço de enunciação. GUIMARÃES, 2005).

O dizer do locutor-Ministro significa a "cota" como constitucional, por ser uma sentença intermédia ou intermediária. ${ }^{13}$ Contudo, a "cota" também se movimenta para a inconstitucionalidade se não houver adequações no critério "desigual" de seleção. Essa compreensão se assenta no memorável das enunciações sobre o ocorrido no "órgão de

13 Utilizado pela primeira vez na VII Conferência dos Tribunais Constitucionais Europeus, o termo sentenças intermediárias surgiu para designar a resposta dada pelo tribunal da jurisdição constitucional, quando este, muito embora haja identificado uma inconstitucionalidade na norma impugnada, não a declara diretamente, mas promove sua adequação ao texto constitucional. Disponível em http://jus.com.br/artigos/7514/as-decisoes-intermediarias. Acesso em 27 maio 2016. 
seleção racial", ou seja, durante as entrevistas que classificaram pessoas da mesma família em raças diferentes, além de permitir a inclusão de pessoas que socioeconomicamente não necessitam de "cotas", reiterando assim, o já dito na SE1.

Nessa cena, o dizer do locutor-Ministro instala o alocutário-x pelo vocativo $\mathrm{Sr}$. presidente (lugar social de Presidente do STF), ao afirmar que a "cota" "não é bom modelo, especialmente numa "sociedade miscigenada". Significando que os sentidos de "cota" se dispersam e os direitos adquiridos pelo negro, através da "cota", passam a incluir outros segmentos da sociedade pela contradição política no sistema de seleção.

Desse modo, compreendemos que, ao declarar a ação improcedente, mas não afirmar a constitucionalidade da "cota", o dizer do locutor-Ministro recorta o memorável de enunciações já ditas sobre o método de seleção da UnB, projetando sentidos que se contradizem. Assim, a utilização do critério puramente racial significa a "cota" como inconstitucional, mas se a "cota" estiver significando uma sentença intermédia, ou seja, como possibilidade de adequação à Constituição, ela é constitucional. Portanto, cada vez que a expressão "cota" é enunciada os sentidos se movimentam, produzindo uma nova significação, "uma nova temporalização, um novo espaço de conviviabilidade de tempos, sem a qual não há sentido, não há acontecimento de linguagem, não há enunciação". (Guimarães, 2005, p. 12).

\section{Considerações Finais}

Pelas análises da expressão "cota" nos textos dos votos formulados pelos Ministros do Supremo Tribunal Federal-STF no acontecimento de linguagem "Arguição de Descumprimento de Preceito Fundamental 186", observamos que o agenciamento enunciativo do lugar social de locutor, determina e faz variar os sentidos da expressão "cota".

Por exemplo, no R1, a "cota" significa "deveres constitucionais" em oposição a "meras concessões; no R2, a "cota", enquanto uma das medidas das ações afirmativas, é predicada por "imediata e temporária", significando que pode desaparecer à medida que as desigualdades diminuírem, ou seja, por essa visão, as "cotas" podem diminuir, o que não significa que serão erradicadas. Essa contradição entre a "cota" ser constitucional e temporária "estabelece desigualmente uma divisão do real e a afirmação de pertencimento dos que não estão incluídos", na perspectiva de que "o homem está sempre a assumir a palavra, por mais que esta lhe seja negada" (GUIMARÃES, 2005, p. 16). No último recorte, R3, a "cota" produz sentidos de que é parcialmente constitucional, e dadas as distorções que provoca, o dizer locutor-Ministro se posiciona: "Eu tenho dúvida de que esse modelo possa prosseguir [...]".

Notamos que no acontecimento de linguagem "Arguição de Descumprimento de Preceito Fundamental - ADPF", a "cota" adquire vários sentidos, mas não qualquer um, pois o sentido é regulado pelas condições de seu acontecimento: "quem disse o enunciado, em que circunstância, com que objetivo" (DIAS, 2014d, p. 300). 
Dessa maneira, a palavra "cota" projeta uma futuridade de novos sentidos a partir do acontecimento da Arguição de Descumprimento de Preceito Fundamental ADPF186, pois possibilita a instituição e continuação dessa ação afirmativa por meio da Lei $n^{\circ} 2.711$, de 29 de agosto de $2012^{14}$, que além de assegurar o ingresso para os autodeclarados pretos, pardos, indígenas, incluiu também o critério socioeconômico (renda per capita /escola pública) no sistema de "cotas" das universidades federais.

\section{Referências bibliográficas}

ALBUQUERQUE, Wlamyra R.; FILHO, Walter. F. Uma história do negro no Brasil. Salvador: Centro de Estudos Afro-Orientais; Brasília: Fundação Cultural Palmares, 2006.

AMORIM, D. Teorias raciais no Brasil: um pouco de história e historiografia. Revista Cantareira: Dossiê história e meio ambiente. Ed. 19, jul-dez, 2013. Disponível em http://www.historia.uff.br/cantareira/v3/wp-content/uploads/2014/11/e19a06.pdf.

Acesso em 9 jan. 2017.

BRASIL. Supremo Tribunal Federal (STF). Regimento interno [atualizado até dezembro de 2015; consolidado e atualizado até maio de 2002 por Eugênia Vitória Ribas]. Brasília: $\quad$ STF, 2015. Disponível em http://www.stf.jus.br/arquivo/cms/legislacaoRegimentoInterno/anexo/RISTF.pdf.

Acesso em 15 maio 2016.

CASHMORE, Ellis. Dicionário de relações étnicas e raciais. São Paulo: Sumus, 2000.

DIAS, L. F. Sentido, significado e significação. Em: FRADE, Isabel; VAL, Maria; BREGUNCI, Maria. (Orgs.). Glossário Ceale: termos de alfabetização, leitura e escrita para educadores. Belo Horizonte, MG: UFMG, 2014.

FURLAN, Oswaldo. A. Latim para o português: gramática, língua e literatura. Florianópolis, UFSC, 2006.

GUIMARÃES, Eduardo. Análise de texto. Procedimentos, análises, ensino. Campinas: Editora RG, 2011.

Os limites do sentido: um estudo histórico e enunciativo da linguagem. $4^{\mathrm{a}}$. ed. Campinas, Editora RG, 2010.

Semântica do acontecimento: um estudo enunciativo da designação. Campinas, SP: Pontes, 2005.

et. al. Multilinguísmo, divisões da língua e ensino no Brasil. Campinas, Editora

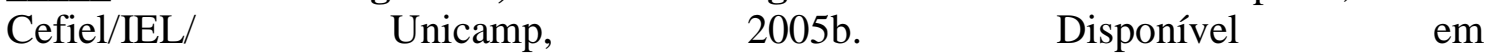
https://www.google.com.br/url?sa=t\&rct=j\&q=\&esrc=s\&source=web\&cd=1\&cad=rja\& uact=8\&ved=0ahUKEwiVx6q_98zTAhWBG5AKHYP3BAYQFggmMAA\&url=http\%

\footnotetext{
${ }^{14}$ Disponível em http://portal.mec.gov.br/cotas/perguntas-frequentes.html. Acesso em 02 nov. 2016.
} 
3A\%2F\%2Fpaginapessoal.utfpr.edu.br\%2Fsilvanaayub\%2Fcelem_2012\%2Fartigos\%2 F21_Multilinguismo $\% 2520 \mathrm{e} \% 2520$ Ensino.pdf $\% 2 \mathrm{Fat}$ download $\% 2$ Ffile\&usg=AFQjCN F-DX384Lchr1lmZzKS-o9-iOvgpw. Acesso em 10 maio 2016.

HOUAISS, A.; VILLAR, M. Dicionário Houaiss Eletrônico. 2009.

NORÕES, Katia. C. Cotas raciais ou sociais? Trajetória, percalços e conquistas na implementação de ações afirmativas no ensino superior público (2001-2010). Dissertação. Mestrado em Educação. FE, UNICAMP, Campinas, 2011.

OLIVEIRA, D.R. Argumentação, linguagem e história:sentidos à carta testamento de Vargas. Língua e Instrumentos Linguísticos, Campinas, SP, RG, 91-106, 2013. Disponível em http://www.revistalinguas.com/edicao31/artigo6.pdf; acesso em 20 maio 2016.

SANTOS, Sales. A. Movimentos negros, educação e ações afirmativas. Tese. Doutorado em Sociologia. Universidade de Brasília, 2007.

VASCONCELOS, Almeida. O debate sobre a questão racial no Brasil urbano: passado e presente. Revista Bibliográfica de Geografia Y Ciencias Sociales (Serie documental de Geo Crítica), Universidad de Barcelona, vol. XII, nº. 729, 15/06/2007. Disponível em http://www.ub.edu/geocrit/b3w-729.htm; acesso em 4 jan. 2017.

Artigo recebido em: julho de 2016.

Aprovado e revisado em: novembro de 2016.

Publicado em: abril de 2017.

Para citar este texto:

SOUZA, Thalita Nogueira de; ZATTAR, Neuza B. da Silva. Os sentidos de "cota" no julgamento da arguição de descumprimento de preceito fundamental-ADPF 186. Entremeios [Revista de Estudos do Discurso, on-line], Seção Estudos, Programa de PósGraduação em Ciências da Linguagem (PPGCL), Universidade do Vale do Sapucaí (UNIVÁS), Pouso Alegre (MG), vol. 14, p. 23-36, jan. - jun. 2017.

DOI: http://dx.doi.org/10.20337/ISSN2179-3514revistaENTREMEIOSvol14pagina23a36 